\title{
Os processos de formação superior e encontrados na extração de cores do ecossistema
}

Los procesos de formación superior y su inciden en la extracción de corales del ecosistema

Higher education processes and their impact on the extraction of corals from the ecosystem

\section{Edilson Gonçalves}

Ph.D. Pontifícia Universidade Católica de São Paulo, São Paulo, Brasil. https://orcid.org/0000-00021157-1445, eedilsongoncalves@me.com

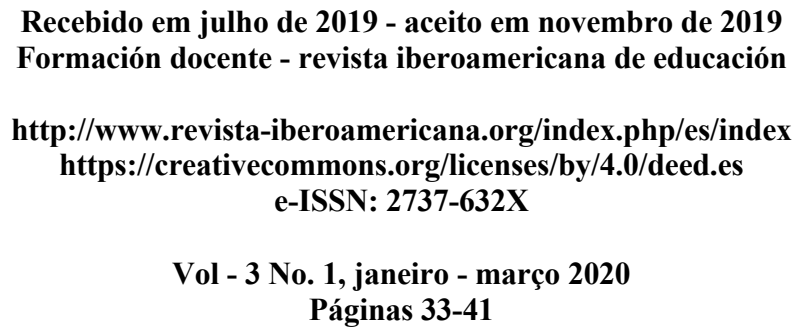

Resumo A comuna Ayangue caracteriza-se por ser uma área turística, por sua gastronomia e diversidade na fauna marinha, uma vez que encontramos uma variedade de espécies. Uma dessas espécies são os corais, que são animais marinhos muito especiais. A falta dessas espécies não só prejudica o ambiente biótico, mas também os turistas, pois nos protegem de tempestades ou outros aspectos que ocorrem no mar. Este projeto foi realizado por uma série de investigações de campo, tais como: descritiva e analítica; da mesma forma bibliográfica. Foram feitas observações diretas nas amostras, também através de uma pesquisa para analisar e aprender mais sobre os corais. Foram determinados os fatores incidentes na extração de corais no ecossistema marinho da praia de Ayangue, sendo o principal a economia da comuna, uma vez que esses animais podem ser comercializados através de ornamentos, colares e outras bijuterias. Outro fator é que a população não conhece a importância 
dos corais no ambiente marinho e, portanto, os extrai como uma simples atração. A população não possui conhecimento adequado desses animais. Por outro lado, sabe-se que há poluição marinha nesta praia por indústrias próximas à população, além de shopping centers e lixo descartado pelos turistas. A população deve ser conscientizada por meio de palestras voltadas à proteção da vida marinha, como tema principal, corais; motivar as pessoas a não extrair essas espécies, mas saber usá-las; incentivar os turistas a não jogar lixo na praia e respeitar o ecossistema marinho.

Palavras chaves corais, fatores, extração, turismo, poluição, praia

Resumen La comuna Ayangue se caracteriza por ser zona turística, por su gastronomía y diversidad en la fauna marina, ya que encontramos variedad de especies. Una de estas especies son los corales, que son animales marinos muy especiales. La falta de estas especies no solo perjudica al medio biótico sino también a los turistas ya que las mismas nos protegen de marejadas u otros aspectos que se presenten en el mar. El presente proyecto se realizó por una serie de investigaciones de campo como: descriptiva, y analítica; así mismo bibliográfica. Se realizó observaciones directas a las muestras, también por medio de encuesta para analizar y conocer más sobre los corales. Se determinó los factores incidentes en la extracción de corales en el ecosistema marino de la playa de Ayangue, el principal es la economía de la comuna, ya que éstos animales se pueden comercializar por medio de adornos, collares, y demás bisutería. Otro factor es que la población no conoce la importancia de los corales dentro del medio marino y por lo tanto los extraen como simple atracción. La población no tiene el conocimiento adecuado de estos animales. Por otro lado se conoce que en ésta playa hay contaminación marina por parte de industrias cercanas a la población, así mismo por centros comerciales y la basura desechada por los turistas. Hay que 
concientizar a la población por medio de charlas encaminadas a la protección de la vida marina, como principal tema, los corales; motivar a las personas que no extraigan éstas especies sino saben cómo utilizarlas; incentivar a los turistas que no arrojen basura en la playa y que respeten el ecosistema marino.

Palabras clave: : corales, factores, extracción, turismo, contaminación, playa

Abstract. Ayangue is known for being a tourist area, for its gastronomy and diversity in marine fauna, as we find a variety of species. One of these species are corals, which are very special marine animals. The lack of these species not only harms the biotic environment but also the tourists as they protect us from tides or other aspects that appear at sea. The present project was realized by a series of field investigations as: descriptive, and analytical; As well as bibliographical. Direct observations were made to the samples, also by means of a survey to analyze and to know more about the corals. The factors involved in the extraction of corals in the marine ecosystem of Ayangue beach were determined, the main one being the economy of the commune, since these animals can be commercialized by means of ornaments, necklaces, and other costume jewelery. Another factor is that the population does not know the importance of corals within the marine environment and therefore extract them as a simple attraction. The population does not have adequate knowledge of these animals. On the other hand it is known that on this beach there is marine pollution by industries close to the population, as well as shopping malls and garbage discarded by tourists. The population must be made aware through talks aimed at the protection of marine life, as the main theme, corals; Motivate people who do not extract these species but know how to use them; 
Encourage tourists who do not throw garbage on the beach and respect the marine ecosystem.

Key words: corals, factors, extraction, tourism, pollution, beach.

\section{INTRODUÇÃO}

A província de Santa Elena é conhecida como o perfil costeiro mais visitado pelos turistas que partem do cantão de Salinas, onde encontramos as praias de Santa Rosa e Anconcito. No cantão de La Libertad, Puerto Lucia e Cautivo se destacam e, em Santa Elena, temos San Pablo, Montañita e Ayangue como referência, este último com uma área de aproximadamente $1.000 \mathrm{~m}$. longo e é considerado um local turístico.

A comuna Ayangue caracteriza-se por ser uma área turística, por sua gastronomia e diversidade na fauna marinha, uma vez que encontramos uma variedade de espécies. Uma dessas espécies são os corais, animais marinhos muito especiais para começar, que possuem o esqueleto do lado de fora (exoesqueleto). Ao contrário de nós, seres humanos que têm o esqueleto dentro. Os corais têm exoesqueletos rochosos, formados por carbonato de cálcio, também conhecidos como corais pedregosos. Os corais que têm o exoesqueleto flexível são chamados de corais de chifre ou corais moles. (Ortiz, 2005, p. 6)

Os corais contêm grandes quantidades de dinoflagelados simbióticos conhecidos como zooxantelas na gastroderme; algas que desempenham um papel decisivo no desenvolvimento normal dos pólipos de coral e constituem uma das principais fontes de produção primária. (Gómez Luna, 2003, p. 46)

A falta dessas espécies não só prejudica o ambiente biótico, mas também os turistas, pois nos protegem de tempestades ou outros aspectos que ocorrem no mar. 
O branqueamento causado pelas mudanças climáticas não é a única ameaça aos recifes de coral. Cientistas, autoridades administrativas temem que o estresse do crescimento introduzido pelas atividades humanas esteja contribuindo para o declínio dos recifes globalmente. (Westmacott, Teleki, Wells \& West, 2000, p. 5)

Quando as águas absorvem quantidades crescentes de dióxido de carbono da atmosfera, a acidez da água do mar aumenta, o que orienta um impacto negativo na capacidade das águas residuais que chegam ao continente como resultado da má gestão dessas águas ricas em potássio. e o nitrogênio chega aos mares e impulsiona o crescimento excessivo de algas, um dos inimigos mortais dos corais. (Acosta, 2010)

A caça submarina, por exemplo, causa danos ao removê-los seletivamente da cadeia alimentar desse ecossistema. As âncoras dos barcos mal usados destroem, em questão de segundos, séculos de crescimento de corais e importantes comunidades de peixes. (Acosta, 2010)

A existência de mergulhadores negligenciados pode tocar e quebrar o coral; os turistas são responsáveis pelo enorme crescimento do comércio de curiosidades marinhas, especialmente por espécies ameaçadas, como o coral preto. Além de serem habitats insubstituíveis, como os recifes, são quebramares naturais que se auto reparam e protegem a costa, sem nenhum custo para o homem. (Acosta, 2010)

Para garantir sua persistência, um elemento importante no gerenciamento desses recursos é a conscientização do cidadão sobre a importância desses ecossistemas vulneráveis e os cuidados que eles merecem por sua proteção.

\section{MATERIAIS E MÉTODOS}

A presente investigação foi realizada na comuna de Ayangue, determinada por uma série de investigações de campo, tais como: descritiva e analítica; da mesma forma bibliográfica. Foi aplicado o método dedutivo e indutivo, que 
nos ajudou a coletar informações para submetê-las a uma análise sobre o assunto de fatores que afetam a extração de corais do ecossistema marinho na comuna de Ayangue. As amostras foram observadas diretamente, foram as encontradas à beira-mar, também por meio de uma pesquisa para analisar e aprender mais sobre os corais existentes na comuna de Ayangue e seu ecossistema marinho.

O projeto é voltado para a população da comuna de Ayangue, trabalhou com pesquisas: havia 10 turistas e 10 habitantes do local para obter as informações que eles tinham sobre os corais no ecossistema marinho e em seu ambiente. Para a presente investigação, 20 pessoas da comuna Ayangue foram pesquisadas para obter informações sobre esse recurso, uma vez que é usado como ornamento e, por sua vez, o coral é essencial para a vida marinha.

Essa técnica foi realizada por meio de um questionário adequado que nos permite coletar dados de uma amostra da população.

Nesse caso, usamos perguntas concisas e com as quais eles têm opções para responder com perguntas fechadas e específicas.

\section{RESULTADOS}

Dentre os valores altos, temos as questões 1, 4,5 e 6. Sendo cinco um valor alto com $90 \%$ dos habitantes pesquisados, eles pensam que deve haver regras que defendam o ecossistema e $10 \%$ que indicam que eles não deveriam existir. o mesmo desde que não permanecessem sem extrair o recurso. Da mesma forma, a primeira pergunta nos dá um resultado negativo, indicando que $75 \%$ não sabem da existência do recurso e $25 \%$ sabem. Foi possível determinar quais são os fatores incidentes na extração de corais no ecossistema marinho da praia de Ayangue, o principal é a economia da comuna, uma vez que esses animais podem ser comercializados através de ornamentos, colares e outras bijuterias. Outro fator é que a população não conhece a importância dos corais no ambiente marinho e, portanto, os extrai como uma simples atração. O ambiente marinho da comuna de Ayangue foi 
reconhecido e foi determinado que existe uma grande contaminação marinha por indústrias no nível costeiro e pelos habitantes, como o lixo encontrado. E que os corais são afetados pela temperatura e salinidade da água, afetam sua emergência nas margens das praias.

Por meio de pesquisas realizadas em uma pequena amostra da população, analisou-se a situação atual dos corais, afirmam as pessoas que são extraídas para diversas coisas, como para o artesanato e a medicina. De acordo com a pesquisa bibliográfica, foi possível determinar que esses organismos, no estágio da larva, estão fixados a uma superfície sólida, como pedras, outros corais ou areia estabilizada por plantas marinhas. Os recifes de coral são recursos inestimáveis para as comunidades locais que servem como fonte de alimento, emprego e estilo de vida, bem como para a proteção costeira. Pesca, turismo, a descoberta de novas drogas e a proteção que os recifes de coral oferecem para mitigar o impacto das mudanças climáticas são apenas alguns dos benefícios proporcionados por essas belas obras da natureza.

\section{CONCLUSÕES}

Foi especificado que os fatores incidentes na extração de corais são: economia da comuna, uma vez que são comercializados em artesanato, etc., ignorância da importância dessas espécies no ambiente marinho. Além disso, foi determinado que a população não possui conhecimento adequado desses animais. Por outro lado, sabe-se que há poluição marinha nesta praia por indústrias próximas à população, além de shopping centers e lixo descartado pelos turistas. Deve-se enfatizar que a extração de corais pode ser benéfica no campo da medicina, pois permite a descoberta de novos medicamentos; bem como ajuda econômica à população com a comercialização de produtos feitos de corais.

\section{REFERENNCIAS}

Acosta, J. (03 de Noviembre de 2010). EcoPortal.net. Obtenido de Corales en peligro... Principio de una muerte anunciada. 
Aguilar, V. 2003. Aguas continentales y diversidad biológica en México: un recuento actual. Biodiversitas 48: 1-15. Alcorn, J. 1984. Development policy, forests and peasant farms

Carrillo, J., y C. Schatan (comps). 2005. El medio ambiente y la maquila en México: un problema ineludible, Comisión Económica para América Latina y el Caribe, México

Cendra Garreta, J., y A.W. Stahel. 2006. Hacia una construcción social del desarrollo sostenible basada en la definición de sus dimensiones y principios, articulados a partir de la ecuación IPAT. Aproximación a sus implicaciones y debates. Revista Internacional de Sostenibilidad, Tecnología y Humanismo 1: 1-32.

Challenger, A. 1998. Utilización y conservación de los ecosistemas terrestres de México: Pasado, presente y futuro. Conabio-Instituto de Biología, unam-Agrupación Sierra Madre, México.

El cambio climático y sus efectos en la biodiversidad en América Latina Eduardo Uribe Botero, LC/W.693 Copyright (C) Naciones Unidas, diciembre de 2015. Todos los derechos reservados Impreso en Naciones Unidas, Santiago S.15-01295

Gómez Luna, L. (2003). Identidad y medio ambiente: enfoques para la sustentabilidad de un bien común. Argentina: Siglo XXI.

INP. 1998. Atlas pesquero de México, Instituto Nacional de Pesca, México. INP. 2007. Participación del Inapesca en el proyecto EP/GLO/ 201/GEF de la FAO. Boletín del Instituto Nacional de Pesca.

Martínez-Ramos, M. 1994 Regeneración natural y diversidad de especies arbóreas en selvas húmedas. Boletín de la Sociedad Botánica de México 54: 179-224

Ortiz, Á. (2005). Los arrecifes de coral. Puerto Rico: Sea Grant.

Rodríguez Morales, A., Barros Bastida, C., \& Milanés Gómez, R. (2019). Profesionalización docente y formación desde un nuevo currículo en la 
Universidad de Guayaquil. Revista Universidad y Sociedad, 11(1), 243-248.

Tapia-León, M., Rivera Villalta, M. D. C., Luján-Mora, S., \& Barros Bastidas, C. I. (2017). Análisis de la calidad de los resúmenes de tesis de grado de las universidades del Ecuador respecto a normas internacionales.

von Feigenblatt, Otto Federico, ASEAN and Human Security: Challenges and Opportunities (July 29, 2009). Ritsumeikan Center for Asia Pacific Studies Working Paper, No. 09-5, Available at SSRN: https://ssrn.com/abstract=1442476 or http://dx.doi.org/10.213 9/ssrn.1442476

von Feigenblatt, Otto Federico, Japanese Animation as a Global Product: The

Lingering Traces of Nijonjinron and the Rise of Globalism and Hybridity (August 2, 2012). Journal of History \& Social Sciences, 2(2), pp. 1-14, July-December 2012, Available at

SSRN: $\underline{\text { https://ssrn.com/abstract=2195562 }}$

von Feigenblatt, Otto Federico, Garcia Marquez' Magical Realism as a Representation of Latin America's Socio-Political Reality: Developmental Simultaneity and Exceptionalism in Latin America as Expressed in Historiographic Metafiction (December 27, 2009). The Expression, Vol. 2, No. 1, pp. 1-6, 2009, Available at SSRN: https://ssrn.com/abstract $=1596690$

Westmacott, S., Teleki, K., Wells, S., \& West, J. (2000). Manejo de Arrecifes de Coral Blanqueados o Severamente Dañados. Cambridge: Informatio Press, Oxford, UK. 